Katrina's Imprint 


\section{Rutgers Studies in Race and Ethnicity}

Controversies in race and ethnicity cannot be fully understood through a single analytical lens or disciplinary approach. Such issues require sustained, collaborative analysis-drawing on insights from law to history, from sociology to literature, from labor studies to anthropology, from political science to healthrelated scholarship, and from biology to cultural studies. Focusing primarily on edited volumes, the series aims to bring multiple theories, methods, and approaches to bear on how racial and ethnic politics, identity, culture, structures, and social relations function in the modern world. Through innovative critical commentary and sustained policy engagement, this series encourages scholarship aimed at expanding and deepening the study of these issues in the United States and around the globe. Organized by the Rutgers Center for Race and Ethnicity, the series is an outgrowth of the breadth, depth, and strength of the field at the University and is committed to new collaborative scholarship that bridges boundaries. Readers will find a deep and expansive understanding of the intricate and often unrecognized ways in which race and ethnicity shapes and is shaped by modern societies.

Series Editors: Keith Wailoo, Karen M. O’Neill, Mia Bay, and Lisa Miller

Keith Wailoo, Karen M. O'Neill, Jeffrey Dowd, and Roland Anglin, eds., Katrina's Imprint: Race and Vulnerability in America 


\title{
Katrina's Imprint
}

Race and Vulnerability in America

\author{
EDITED BY \\ KEITH WAILOO \\ KAREN M. O'NEILL \\ JEFFREY DOWD \\ ROLAND ANGLIN
}

RUTGERS UNIVERSITY PRESS 
Katrina's imprint : race and vulnerability in America / edited by Keith Wailoo ... [et al.].

p. cm. - (Rutgers studies in race and ethnicity)

Includes bibliographical references and index.

ISBN 978-O-8I35-4773-2 (hbk. : alk. paper) - ISBN 978-O-8I35-4774-9 (pbk. : alk. paper)

I. Hurricane Katrina, 2005-Social aspects. 2. Disaster relief-Social aspects-Louisiana-New Orleans. 3. Disaster relief-Social aspects-Gulf States. 4. United States-Social conditions-2Ist century. I. Wailoo, Keith. HV636 2005 .N4 K38 2010 $976^{\prime} .044-\mathrm{dc} 22$ 2009038466

A British Cataloging-in-Publication record for this book is available from the British Library.

This collection copyright (C) 2010 by Rutgers, The State University of New Jersey Individual chapters copyright (C) 2010 in the names of their authors

All rights reserved

No part of this book may be reproduced or utilized in any form or by any means, electronic or mechanical, or by any information storage and retrieval system, without written permission from the publisher. Please contact Rutgers University Press, IOo Joyce Kilmer Avenue, Piscataway, NJ 08854-8099. The only exception to this prohibition is "fair use" as defined by U.S. copyright law.

Visit our Web site: http://rutgerspress.rutgers.edu Manufactured in the United States of America 